\title{
Leitoras a escritoras: uma viagem pelo ciberespaço
}

\author{
Profa. Dra. Regina Helena M. A. Corrêa \\ $\mathrm{UEL} / \mathrm{CLCH} / \mathrm{LET}$ \\ correa_regina@hotmail.com
}

Há mais de meio século a escrita de autoria feminina tem sido alvo de interesse, em vários níveis acadêmicos. Dentre as mais diversas razões que justificam esses estudos, vê-se o destaque para a análise de um discurso feminino revelador de opressões impostas por uma sociedade essencialmente dominada por homens, evidenciando questões de identidade e desterritorialização. Perpassam esses estudos iniciativas acadêmicas memoráveis, em termos de ampliação das discussões em torno do assunto, como a criação de grupos de trabalho, núcleos de estudo e seminários periódicos. A pesquisadora Constância Lima Duarte destaca como iniciativas brasileiras, que ocorreram no final dos anos de 1970 e ao longo dos anos de 1980:

É desta época a criação do Grupo de Trabalho sobre Estudos da Mulher da Anpocs, e do Grupo de Trabalho Mulher na Literatura, da Anpoll; assim como a criação do NEM - Núcleo de Estudos sobre a Mulher, da PUC-RJ; do Neim - Núcleo de Estudos Interdisciplinares sobre a Mulher, na UFBA; do Nielm - Núcleo Interdisciplinar de Estudos da Mulher na Literatura, da UFRJ: e do Nemge - Núcleo de Estudos da Mulher e Relações de Gênero, da USP; entre muitos outros que se multiplicaram nas diferentes instituições de ensino superior, enfrentando resistências e desconfianças para cumprir a função de agregar os(as) interessados(as) na temática, promover o desenvolvimento da pesquisa e do estudo de temas relevantes para as mulheres, e principalmente, impulsionar a publicação de trabalhos e preencher a enorme carência bibliográfica de que todos se ressentiam (2003, p. 167).

Uma iniciativa posterior, mas que merece também destaque é a Editora Mulheres, fundada por três professoras da Universidade Federal de Santa Catarina, que afirmam ser "preocupadas com a memória cultural e com a história literária”, que tenham como foco temático "Literatura e Mulher".

Quando se observa a história da luta feminina por igualdade de direitos, percebe-se que ela é marcada não apenas pelo enfrentamento de desafios, mas também pela capacidade de aproveitar oportunidades que se mostraram fundamentais para muitas de suas conquistas. Hoje, a história segue por outros caminhos, mas não menos importante, quando se volta a 
atenção para o grande fenômeno sócio-cultural provocado pela democratização dos meios eletrônicos de comunicação. O ciberespaço tem permitido, além do acesso mais rápido e amplo à informação, uma verdadeira revolução em termos do uso da palavra escrita. As relações sociais, rapidamente, estão se tornando, a cada dia, mais dependentes do que se chama atualmente de letramento, através de emails, chats, blogs, Twitter, Facebook, ou mesmo mensagens em celulares.

Se antes, para divulgar as suas produções, dependia-se de um meio impresso qualquer de circulação, hoje os indivíduos criam os seus próprios espaços, fazem a sua própria propaganda e, algumas vezes, alcançam sucesso sem qualquer apoio de grandes meios de comunicação. É nesse viés, portanto, que este trabalho pretende caminhar, discutindo o ciberespaço como elemento facilitador do amplo crescimento da escrita feminina no Brasil, nos últimos anos. Visto que a definição de ciberespaço é muito mais ampla do que simplesmente aquela de sítios na rede de alcance mundial (world wide web), pretende-se delimitar a discussão a academias, associações, páginas individuais, blogs públicos e privados, que são espaços virtuais utilizados por aquelas que se definem como escritoras.

\section{Ciberespaço: heróis e bandidos}

Nos anos 90, o desenvolvimento da world wide web veio trazer grandes mudanças na comunicação pessoal e, consequentemente, na relação entre o produtor e o leitor de textos. Aos poucos se descobriu a internete como um meio completamente diferente de outras mídias, dada a rapidez de difusão de dados e a possibilidade de interação em tempo real. Enquanto o computador levou dezesseis anos para ser amplamente utilizado, a Internet, por sua vez, em apenas quatro anos, segundo pesquisa divulgada em 2008 pela IDGNow!, conseguiu atingir mais de 50 milhões de usuários. Em maio de 2009, o Ibope informou que o país possuía 62,3 milhões de usuários. Hoje, o número de usuários de internet no mundo alcançou os dois bilhões de pessoas, conforme fala de Hamadun Touré (2011), chefe da União Internacional de Telecomunicações (UIT) no artigo “Conectados do mundo já chegam a 2 bilhões”, publicado na Gazeta do Povo.

É fato que a internete tornou-se ferramenta indispensável em todas as áreas do conhecimento, em diversas formas de negociação, pela sua capacidade de distribuição mais 
rápida de dados e informações. Há um número considerável de páginas da internete acessadas diariamente por usuários de todas as faixas etárias e com vários níveis de escolaridade. O material em circulação é bastante variado: simples contatos através de e-mails, conversas em salas de bate-papo, fotos pessoais e depoimentos pessoais nos fotologs e blogs, comunidades virtuais, fóruns de discussões acadêmicas, sítios pessoais, comerciais e acadêmicos, e tantas outras situações em que a wmw assumiu papel de destaque. Como afirma Heloísa Buarque de Hollanda, "é possível identificar que o uso da Internet vem se constituindo como um importante fator que vem alterando e ao mesmo tempo vem sendo retransformado pela referência cultural, atualizando hábitos, costumes e relações de trabalho" (25/08/??).

A aplicabilidade da rede hoje é tão vasta que não existe mais possibilidade de controle desse ambiente cibernético, provocando sentimentos conflitantes naqueles que defendem a livre expressão. A falta de controle sobre a circulação de dados tem causado uma sensação de desconforto e de insegurança, pela ausência de exata noção de quanto e como tal liberdade e facilidade de expressão pode nos afetar individualmente ou como grupo, a exemplo do escândalo diplomático em conseqüência do vazamento de documentos confidenciais do governo americano publicados no site wikileaks.

Por outro lado, aqueles que se sentiam ameaçados diante da possibilidade de ver rapidamente o fim do livro e dos leitores estão presenciando uma grande revolução em termos de leitura e escrita. O que se observa, nos últimos anos, é uma nítida inversão das previsões aterrorizantes resultantes da popularização da televisão e dos aparelhos audiovisuais. A expectativa de que estávamos caminhando para uma sociedade fundada na audição e na imagem e que a escrita tenderia a se tornar obsoleta mostrou-se absolutamente infundada. O que se observa é que a comunicação está mais centrada na escrita e, consequentemente, na leitura. Jornais, revistas, blogs, correspondências eletrônicas, páginas de relacionamento pessoal e empresarial, programas de mensagens instantâneas, e tantas outras atividades do mundo moderno, dependem exclusivamente do letramento, da capacidade do indivíduo de ler e se comunicar na forma escrita. As próprias relações interpessoais se tornaram dependentes da escrita, pelos muitos estímulos sócio-interacionais que tornam a escrita/leitura instigante: as postagens em páginas pessoais, as conversas nas salas de bate-papo e nos programas de mensagens instantâneas, assim como as mensagens de texto nos celulares, um meio de alta popularidade no Brasil, por ser uma alternativa mais barata e, em alguns casos, muito mais 
conveniente do que a chamada telefônica móvel. Certo está que muitos usuários ainda utilizam as ferramentas de interação apenas quando podem fazer uso de voz e vídeo, pela incapacidade de escrever ou de reagir rapidamente aos estímulos interativos da escrita online. $\mathrm{Na}$ área acadêmica em geral, a internet também trouxe muitos benefícios, ainda que combatidos por uma parcela dessa comunidade que se mostra avessa ao uso da tecnologia, demonstrando em seu discurso um pseudoconservadorismo, pois se utilizam de outras tecnologias interativas, como telefone fixo e móvel, caixas de automação bancária, totens de informação, etc.

A Internet tem se tornado uma tribuna aberta ao exercício e difusão da escrita, ou como afirma Pedro de Souza, professor do CCE/UFSC:

Observa-se nesta nova tecnologia de expressão uma democratização do acesso à escrita e uma ampliação do espaço para pôr em circulação o que se escreve. Neste sentido, a era digital abre-se como uma solução para muitos que, embora escrevendo continuamente em qualquer domínio das práticas culturais - literatura, ciências, jornalismo -, nem sempre têm oportunidade de ver seus escritos publicados. Em verdade as novas tecnologias de difusão tornam visível o que uma vez, ironicamente, constatou Butor, ou seja, o fato de que em nossa sociedade todo o mundo escreve um pouco, ainda que não faça literatura (2004).

O escritor internauta desfruta não apenas da liberdade de divulgar o seu material, sem que haja qualquer mediação das suas produções, como também da facilidade de publicar (no sentido de tornar pública a sua produção) e de publicizar (que está na área da publicidade ou de divulgação) os seus escritos com muita rapidez e para uma grande quantidade de leitores. Se antes a liberdade do escritor se limitava a ele próprio pagar a impressão de seus livros ou reproduzi-los em mimeógrafos e copiadoras para distribuí-los a amigos e parentes (que muito em breve generosamente doavam ao sebo ou à biblioteca mais próxima), o mundo cibernético permite a divulgação imediata, com pouco esforço e de forma interativa, na medida em que os leitores podem contribuir com críticas e discussões quase em tempo real.

Os escritores internautas não mais dependem de revistas, jornais ou livros, com o crivo de autoridades acadêmicas ou de filtros comerciais (editores, patrocinadores, avaliadores e críticos), para a divulgação de sua produção intelectual. A produção "internáutica" é facilitadora do contato do escritor com o público leitor, que muitas vezes assume o papel de crítico literário e de co-autor. A interlocução com os internautas, através de listas de 
discussões, dos contatos por meio de endereços eletrônicos deixados nas homepages, e mesmo com os seguidores da produção literária on-line, tem demonstrado ser uma experiência com resultados positivos. Para quem leu A Vida Literária no Brasil- 1900 de Brito Broca (1975), não é difícil perceber que a internete assumiu o papel das antigas discussões em universidades, nas portas das livrarias, nas bibliotecas, em salões literários, em confeitarias e cafés, em bares, e tantos espaços culturais especialmente criados para esse fim ou sabiamente improvisados para fazer efervescer a vida literária. A história se repete apenas renovada tecnologicamente, possibilitando, portanto, uma releitura desses momentos.

\section{Espaços femininos}

A pesquisadora Constância Lima Duarte, no artigo "Feminismo e Literatura: discurso e história” (2003-2004), destaca alguns pontos interessantes sobre os avanços conquistados pelas mulheres especialmente a partir do séc. XIX, no Brasil. Segundo a autora, a primeira legislação que autoriza a abertura de escolas públicas femininas data de 1827. Até então a educação de mulheres se concentrava em conventos, considerados lugar seguro para as moças à espera de casamento, escolas particulares nas casas de professoras, ou o ensino individualizado, mas sempre tendo como objetivo principal o ensino de prendas domésticas. Duarte também aponta que foram as primeiras mulheres formalmente educadas, para questões que ultrapassavam o ambiente doméstico, que começaram a abrir escolas, publicar livros, escrever para jornais e questionar a idéia de que mulher não necessitava saber ler nem escrever (2003-2004: pág. 198).

Duarte destaca o papel importante de Nísia Floresta como "uma das primeiras mulheres no Brasil a romper os limites do espaço privado e a publicar textos em jornais da chamada 'grande' imprensa. Direitos das mulheres e injustiça dos homens (1832), primeiro livro de Nísia Floresta, é também o primeiro no Brasil a tratar do direito das mulheres à instrução e ao trabalho, e a exigir que elas fossem consideradas inteligentes e merecedoras de respeito" (20032004: pág. 198-199).

Ainda conforme Duarte, em cerca de meio século, a educação formal feminina, influenciada pelos movimentos feministas nos EUA e na Europa, impulsionou não apenas a abertura de várias escolas, como também a criação de um espantoso número de jornais e revistas de feição nitidamente feminista, editados no Rio de Janeiro e em outros pontos do país, e que se caracterizaram como importantíssimos para a conscientização da população feminina. A pesquisadora enumera várias escritoras importantes na luta pelos direitos das 
mulheres, do início do século XIX ao final do séc. XX. Dentre tantas mulheres importantes, há casos interessantes, como a corajosa Gilka Machado (1893-1980) que desafiou a moral patriarcal e cristã ao publicar, em 1918, Meu glorioso pecado, um livro de poemas eróticos. Rosalina Coelho Lisboa (1900-1975) que, em 1921, conseguiu conquistar o primeiro prêmio feminino no concurso literário da Academia Brasileira de Letras, com o livro Rito Pagão, e foi a primeira mulher a ser designada pelo governo brasileiro para uma missão cultural no exterior, em Montevideu, em 1932. E Rachel de Queiroz, a primeira mulher a entrar para a Academia Brasileira de Letras, que Duarte considera "na vanguarda de sua época ao penetrar no mundo das letras, na redação dos jornais e na célula partidária, espaços entranhadamente masculinos” (pág. 212). Com relação a Queiroz, vale à pena destacar as palavras de Graciliano Ramos, diante da sua genialidade, mencionada por Duarte:

O quinze caiu de repente ali por meados de 1930 e fez nos espíritos estragos maiores que o romance de José Américo, por ser livro de mulher e, o que na verdade causava assombro, de mulher nova. Seria realmente de mulher? Não acreditei. Lido o volume e visto o retrato no jornal, balancei a cabeça: Não há ninguém com esse nome. É pilhéria. Uma garota assim fazer romance! Deve ser pseudônimo de sujeito barbado.

Depois, conheci João Miguel e conheci Raquel de Queirós, mas ficou-me durante muito tempo a idéia idiota de que ela era homem, tão forte estava em mim o preconceito que excluía as mulheres da literatura. Se a moça fizesse discursos e sonetos, muito bem. Mas escrever João Miguel e O quinze não me parecia natural (2003-2004: pág. 212).

Ao longo do século XX, assim como Raquel de Queirós, muitas escritoras se destacaram no mercado editorial. Como exemplo, citam-se aqui apenas algumas como Nélida Piñon, a primeira mulher em 100 anos a presidir a Academia Brasileira de Letras (1996-1997), Adélia Prado, Cora Coralina, Cecília Meireles, Ligya Fagundes Telles, Clarice Lispector, Hilda Hilst, Helena Parente Cunha, Marina Colasanti, Lya Luft, entre tantas outras.

Mas além de várias e importantes escritoras, que conseguiram chegar ao mercado editorial com sucesso de público, há muitas outras mulheres que produziram e produzem textos no anonimato, guardados em papéis, cadernos e diários, que acabam por serem apagados pelo tempo. Lilian Lacerda, em Album de leitura: memórias de vida, histórias de leitoras (2003), afirma que seria um erro pensar que a questão social da mulher a colocou em uma situação passiva. Quando se analisa a história das mulheres percebe-se que além delas serem verdadeiras administradoras da vida na casa e daqueles a ela ligados, elas foram extremamente 
produtivas e capazes de encontrar maneiras para driblar as amarras impostas por uma sociedade patricarcal:

Nesse sentido, os estudos que reconstituem o quadro social da história literária no Brasil problematizam o excesso de rigor das análises tradicionais acerca da condição feminina, no passado. A mulher sempre foi enfocada em condições de submissão e subserviência irrestrita aos maridos quando, na verdade, a historiografia atual sobre a família e o feminino vêm demonstrando a liderança que elas tiveram na administração da vida doméstica, com ou sem a presença dos maridos, nas fazendas e nos sítios espalhados pelas regiões interioranas e no enfrentamento das barreiras sociais e culturais que lhes permitiram a fundação, edição, co-edição e a colaboração em jornais e periódicos diversos, além da publicação de livros de romances, contos, crônicas, poemas e poesias (Lacerda, 2003, pág. 57).

Hoje, apesar das conquistas terem sido muitas, afirmar que não há mais diferenças ou impedimentos seria maquilar realidade. O que se percebe é que a história se repete, seguindo por outros caminhos, apoiada pelo grande fenômeno sócio-cultural provocado pela democratização dos meios eletrônicos de comunicação. Segundo Santaella (2003),

Para compreender essas passagens de uma cultura à outra, que considero sutis, tenho utilizado uma divisão das eras culturais em seis tipos de formações: a cultura oral, a cultura escrita, a cultura impressa, a cultura de massas, a cultura das mídias e a cultura digital. Antes de tudo, deve ser declarado que essas divisões estão pautadas na convicção de que os meios de comunicação, desde o aparelho fonador até as redes digitais atuais, não passam de meros canais para a transmissão de informação. Por isso mesmo, não devemos cair equívoco de julgar que as transformações culturais são devidas apenas ao advento de novas tecnologias e novos meios de comunicação e cultura. São, isto sim, os tipos de signos que circulam nesses meios, os tipos de mensagens e processos de comunicação que neles se engendram os verdadeiros responsáveis não só por moldar o pensamento e a sensibilidade dos seres humanos, mas também por propiciar o surgimento de novos ambientes socioculturais.

As folhas soltas, os cadernos de versos, os diários, estão hoje, em grande número, em páginas da internete, e são em parte estudados pela professora Luiza Lobo, da Faculdade de Letras da URJ, no livro Segredos Públicos - os blogs de mulheres no Brasil (2008), que trata dessa relação da internete com a escrita feminina e como o meio eletrônico transformou a relação entre o público e o privado do universo feminino. Lobo centraliza o seu estudo em dezoito sítios, entre blogs e fotologs, procurando demonstrar que essas páginas representam uma releitura dos antigos diários, inovados ao tornar públicos segredos íntimos. Apesar da pesquisadora 
também enfatizar o caráter ficcional destes diários, a literatura não é o foco principal de seu estudo.

Quando se analisa a participação feminina na área da literatura, verificam-se tanto produções de excelente qualidade, quanto uma supremacia feminina na utilização do ciberespaço para publicação de poemas, contos, crônicas, romances e crítica literária. Entretanto, quando se faz uma rápida análise dos meios convencionais de publicação literária, verifica-se que nos catálogos de editoras as obras literárias impressas escritas por homens superam em grande número aquelas escritas por mulheres. Um passeio rápido por seis Academias de Letras, todas escolhidas aleatoriamente à exceção da Brasileira de Letras, apresentam interessantes resultados, em termos de membros por gênero:

\begin{tabular}{|c|c|c|c|}
\hline Academia & $\begin{array}{ll}\begin{array}{l}\text { Total } \\
\text { cadeiras }\end{array} & \text { de } \\
\end{array}$ & Ocupadas por escritores & Ocupadas por escritoras \\
\hline Brasileira de Letras & 40 & 36 & 4 \\
\hline Mineira de Letras & 40 & 36 & 4 \\
\hline Paulista de Letras & 40 & 34 & 6 \\
\hline Letras de Brasília & 40 & 36 & 4 \\
\hline Paranaense de Letras & 40 & 36 & 4 \\
\hline Letras do Triângulo Mineiro & 40 & 32 & 8 \\
\hline Luso-brasileira de Letras & 50 & 31 & 9 \\
\hline
\end{tabular}

É interessante fazer aqui a ressalva de que a ABL já teve 181 membros desde a sua fundação, mas apenas 6 são mulheres; e a "Academia Luso-brasileira de Letras", com 50 membros, tem 31 homens, 9 mulheres e 10 cadeiras vagas. Por outro lado, a mesma rápida visita a alguns espaços virtuais semelhantes permite perceber não apenas uma supremacia feminina, como também números impressionantes em termos de mulheres que se mostram como poetas, contistas e bloguistas. Como exemplo, podem ser citadas a "Academia Virtual Brasileira de Letras" (90 membros, com 51 mulheres), a "Academia Virtual Sala dos Poetas Escritores" (497 membros, com 291 mulheres), e o "Mural dos Escritores" (799 membros, com 429 mulheres).

Seria discutir o óbvio afirmar que o ciberespaço tem papel fundamental para a literatura no Brasil e no mundo. Além de artigos e livros publicados sobre o assunto, há inúmeros sítios, como o Ciberescritas, da jornalista Isabel Coutinho, cuja coluna existe desde 1996, onde escreve, publica e comenta reportagens "sobre o futuro dos livros, a presença de escritores na Internet e a relação entre as novas tecnologias e a literatura". 
O que aqui se argumenta é que a internete se constituiu em uma daquelas oportunidades de que se falava no início desse artigo, em relação à escrita feminina, com a vantagem de atingir mais facilmente e mais rapidamente um grande número de leitores, masculinos e femininos, e de seguidoras, que se juntam à produção e ao debate, sem que esses escritos se percam ou esperem que algum familiar reconheça a sua qualidade e publique uma edição póstuma. Assim como nos movimentos femininos anteriores, as escritoras se mostram conscientes do papel desempenhado pelo ciberespaço tanto na divulgação de seus trabalhos, quanto do seu papel como multiplicadoras e conscientizadoras, constatáveis em inúmeros blogs, nos quais as autoras discutem variados assuntos, como literatura, política, economia, beleza, e questões sociais refletidas em campanhas que elas ajudam a promover. Este é o caso de escritoras como Jana Lauxen, Cris Passinato e Fernanda França. Lauxen, que também tem um blog de variedades, quando questionada, em entrevista a Gabriel Nepomuceno Vieira para o Portal Literal, se "Um escritor que não utiliza as ferramentas disponíveis pela rede mundial de computadores é um escritor pela metade?”, respondeu:

$\mathrm{Eu}$, enquanto autora iniciante, só tenho a agradecer pela existência da internet.

Sem ela, de que maneira eu, por exemplo, vivendo em uma cidade pequena do interior, sem dinheiro, sem padrinhos, sem eira e nem beira, conseguiria angariar leitores na Bahia, em Minas Gerais, em Moçambique? Nunca. Internet é democracia pura e não tem porque não ser aproveitada. Sempre com inteligência e bom senso, é claro (2009).

A autora Cris Passinato afirma que a internete contribuiu completamente para o seu trabalho e que "não seria ninguém se não fosse ela" (2009). Da mesma forma, Fernanda França (2010), em reportagem de Felipe Tonon, para o Jornal Cidade, sobre o lançamento de seu livro Nove Minutos com a Blanda, afirma que os seus seguidores na internete são a grande oportunidade de divulgar a sua obra - "através do blog as pessoas comentam a obra, elogiam e isso vai passando para os outros leitores e fãs". A autora Vitória Zavalla argumenta: "Você consegue atingir um número maior de pessoas e de vários países. E não precisa de investimentos, afinal, blogs e sites já oferecem alternativas de publicação. Além disso, não vai precisar mexer no texto por conta de exigências das editoras. E o mais importante: você tem contato direto com seus leitores e aprender muito com eles” (2008).

A escritora Ana Maria Ribas, no artigo "Como era o mundo antes da internet", publicado em seu blog argumenta: 
Houve um tempo em que o silêncio gritava, gemia, chorava, esperneava e a gente nem sabia que a internet estava chegando para aproximar as pessoas, para tornar o mundo mais bonito, para dissipar a solidão, para amenizar a saudade, para eternizar momentos felizes, para compartilhar as dores, para incrementar os amores, para estreitar afetos, para ampliar horizontes, para derrubar barreiras, para multiplicar saberes, e para fazer, de cada um de nós, um elo forte nessa corrente mundial de raízes, de asas, e de sangue, sem a qual não saberíamos mais viver [2009?].

Essa consciência, contudo, não se manifesta somente em situações particulares, há muitos espaços definidos como específicos para mulheres e que são descritos pelas suas autoras como especialmente destinados a movimentos em prol da escrita feminina, como os blogs de Lúcia Leiro - Mulher e literatura, Mídia e mulher com reflexões sobre mulheres nos espaços midiáticos, e Mulber e cinema, ou o blog Mulheres que pecam de Claudinha Monteiro, sobre escritoras, compositoras e personagens literárias femininas. Há ainda os sítios mais declarados como o Vila Mulher ou o da REBRA - Rede de Escritoras Brasileiras que afirma ter como objetivo e missão: "o aprimoramento da sociedade brasileira em particular e a da humanidade em geral por meio da divulgação da palavra da mulher". A associação foi fundada "para tentar corrigir a grande injustiça que as mulheres escritoras brasileiras, em particular, e as mulheres brasileiras, em geral, sofreram e continuam sofrendo ao serem permanentemente excluídas dos registros históricos de nossa sociedade".

No entanto, e talvez aqui esteja o argumento mais importante para que se dê a devida importância a essas manifestações literárias de internautas, o meio não altera necessariamente a qualidade do produto, nem muda o estilo da escrita feminina. O tom parece permanecer o mesmo daquele já apontado na literatura feminina impressa: uma linguagem intimista, muitas vezes fundada em memórias, focada em espaços privados, e com uma linguagem, por vezes, sem qualquer pudor. E talvez aqui caiba citar uma de nossas excelentes poetizas, Marlene Andrade Martins, membro 189 da ABVL, que também publica seus poemas em páginas da internete e em seu perfil do Facebook, mas que há 19 anos, em livro impresso, já falava de um tempo que continua presente, apenas se tornou virtual:

\author{
SOU MULHER \\ NO TEMPO \\ EM QUE A MULHER \\ INVEJA O HOMEM \\ E MAIS AINDA \\ A MULHER. (1992: orelha)
}




\section{Obras citadas}

BROCA, Brito. A Vida Literária no Brasil - 1900. Rio de Janeiro: José Olympio, 1975.

DUARTE, Constância Lima. "Feminismo e literatura: discurso e história". O Eixo e a Roda (Belo Horizonte) 9/10 (2003/2004). Disponível em: http://www.letras.ufmg.br/poslit. Acesso em 11/10/11.

FRANÇA, Fernanda. "Sucesso absoluto: Escritora Fernanda França se destaca na Bienal". Entrevista a Felipe Tonon. Jornal Cidade. 21/08/2010. Disponível em http://vilamulher.terra.com.br/escritoras-da-internet-5-1-37-161.html. Acesso em 19/10/11.

HOLLANDA, Heloisa Buarque de. "A academia ao sul do ciberspace”. [25/08/??] Disponível em: http://www.heloisabuarquedehollanda.com.br/?p=349. Acesso em 19/10/11.

LACERDA, Lilian. Álbum de leitura: memórias de vida, bistórias de leitores. São Paulo: Editora UNESP, 2003.

LAUXEN, Jana. "Entrevista com a escritora Jana Lauxen: escrevendo para não se deixar perturbar". Entrevista a Gabriel Nepomuceno Vieira. Portal Liberal. 14/12/09. Disponível em: http://www.portalliteral.com.br/artigos/entrevista-com-a-escritora-jana-lauxen-escrevendopara-nao-se-deixar-perturbar. Acesso em: 11/10/11.

LOBO, Luiza. Segredos públicos: os blogs de mulheres no Brasil. Rio de Janeiro: Rocco, 2006.

MARTINS, Marlene Andrade. O sentido comum das coisas. Belo Horizonte: O Lutador, 1992.

PASSINATO, Cris. "Quem é o escritor? Entrevista com Cris Passinato". Revista Zap. Publicado por Elizabeth Misciasci em 22/09/09. Disponível em: http://www.revistazap.org/entrevistas/crispassinato.php. Acesso em: 11/10/2011.

RIBAS, Ana Maria. "Como era o mundo antes da Internet". [2009?] Disponível em http://www.anamariaribas.com.br/estArtigos.asp?id2=442\&pag=site. Acesso em $11 / 10 / 2011$.

SANTAELLA, Lucia. "Da cultura das mídias à cibercultura: o advento do pós-humano". Revista FAMECOS (Porto Alegre) 22 (12/2003): págs. 23 a 32. Versão online.

SOUZA, Pedro. "A autoria vista sob o suporte tecnológico". Multiciência (Campinas). 2 (2004). Disponível em http://www.multiciencia.unicamp.br /art01_2_i.htm. Acesso em 19/10/11.

ZAVALLA, Vitoria. "Escritoras da Internet". Entrevista ao Vila Mulher. 04/11/2008. Disponível em http://vilamulher.terra.com.br/escritoras-da-internet-5-1-37-161.html. Acesso em: 11/10/2011.

Páginas consultadas - acesso em 20/10/2011:

Academia Brasileira de Letras: www.academia.org.br/ 
Academia Luso-Brasileira de Letras - www.academialbl.org.br/agenda.htm

Academia Mineira de Letras. www.academiamineiradeletras.org.br/

Academia Paranaense de Letras - www.academiapr.org.br/

ACADEMLA PAULISTA DE LETRAS | APL: www.academiapaulistadeletras.org.br/

Academia Virtual Sala dos Poetas e Escritores - www.avspe.eti.br/

Acleb - Academia de Letras de Brasilia - acleb.org.br/

ALTM - Academia de Letras do Triângulo Mineiro - www.hostsh.com.br/pt-br/node/132

AVBL - Academia Virtual Brasileira de Letras - www.avbl.com.br/

Ciberescritas - http://www.ciberescritas.com/

Editora Mulheres - www.editoramulheres.com.br

FACEBOOK - www.facebook.com

Gazeta do Povo - "Conectados do mundo já chegam a 2 bilhões" http://www.gazetadopovo.com.br/ economia/conteudo.phtml?id=1090768.

Midia e Mulher - http://midiaemulher.blog spot.com

Mulher e Cinema - http:/ / mulherecinema.blogspot.com/

Mulher e Literatura - http:/ / mulhereliteratura.blogspot.com

Mulheres que pecam - http://mulheresquepecam.blogspot.com/

Mural dos Escritores - Portal Revista Sócio-Cultural de Escritores - muraldosescritores.ning.com/

REBRA - Rede de Escritoras Brasileiras - http://rebra.org

Vila Mulher - http://vilamulher.terra.com.br 